\title{
Intrahepatic Bile Duct Cancer Pathologic Primary Tumor TNM Finding $v 7$
}

National Cancer Institute

\section{Source}

National Cancer Institute. Intrahepatic Bile Duct Cancer Pathologic Primary Tumor TNM Finding V7. NCI Thesaurus. Code C90184.

A pathologic finding about one or more characteristics of intrahepatic bile duct cancer, following the rules of the TNM AJCC v7 classification system as they pertain to staging of the primary tumor. 